\title{
Review Article \\ Perspectives on Employment Integration, Mental Illness and Disability, and Workplace Health
}

\author{
Nene Ernest Khalema ${ }^{1,2,3}$ and Janki Shankar ${ }^{4}$ \\ ${ }^{1}$ Human Sciences Research Council, Private Bag X41, Pretoria 0001, South Africa \\ ${ }^{2}$ School of Public Health, University of Alberta, Edmonton, AB, Canada T6G $2 R 3$ \\ ${ }^{3}$ School of Built Environment and Development Studies, University of KwaZulu-Natal, Durban 4041, South Africa \\ ${ }^{4}$ Faculty of Social Work, University of Calgary, No. 444, 11044-82 Avenue, Edmonton, AB, Canada T6G OT2
}

Correspondence should be addressed to Nene Ernest Khalema; ekhalema@hsrc.ac.za

Received 4 July 2014; Accepted 3 November 2014; Published 20 November 2014

Academic Editor: John Godleski

Copyright (C) 2014 N. E. Khalema and J. Shankar. This is an open access article distributed under the Creative Commons Attribution License, which permits unrestricted use, distribution, and reproduction in any medium, provided the original work is properly cited.

This paper reviews the literature on the interplay between employment integration and retention of individuals diagnosed with mental health and related disability (MHRD). Specifically, the paper addresses the importance of an integrative approach, utilizing a social epidemiological approach to assess various factors that are related to the employment integration of individuals diagnosed with severe mental illness. Our approach to the review incorporates a research methodology that is multilayered, mixed, and contextual. The review examines the literature that aims to unpack employers' understanding of mental illness and their attitudes, beliefs, and practices about employing workers with mental illness. Additionally we offer a conceptual framework entrenched within the social determinants of the mental health (SDOMH) literature as a way to contextualize the review conclusions. This approach contributes to a holistic understanding of workplace mental health conceptually and methodologically particularly as practitioners and policy makers alike are grappling with better ways to integrate employees who are diagnosed with mental health and disabilities into to the workplace.

\section{Introduction}

Employment is an important social determinant of health and participation in employment can enhance health and wellbeing. Unfortunately, the majority of individuals with serious mental illness are unemployed [1-5]. For those with mental illness who are employed there is increasing evidence that current workplace environments are contributing to the development and/or exacerbation of mental illness and disability $[6,7]$. Limited mental health literacy among employers has been identified as a major barrier to people diagnosed with mental health and related disability (MHRD), making a successful return to work or sustaining employment difficult [8]. Although there is a considerable body of the clinical literature on the experiences of individuals with severe mental health illness in the workplace, much less has been written about an epidemiological approach to understanding employers' perspectives on hiring workers who experience mental illness and related disability and the kinds of support they need for reintegrating these workers in the workplace. A research approach proposed in this paper makes it possible to assess employers' perspectives on employing workers with mental illness and related disability, their attitudes and concerns about employing workers with these conditions, and the kinds of information and support they need to facilitate the worker's return to work. Possible findings will advance the understanding about the kinds of resources and support employers need to promote and how to manage mental health issues in the workplace. They will also contribute to an emerging conceptual framework [9] on employment integration of people with mental illness and the role of employers within this framework. 


\section{Mental Illness, Employment Integration, and Workplace Health}

Unemployment rates among people with serious mental illness range between $80 \%$ and $90 \%$ [ $8-11$ ], making this group one of the most recipients of social security in Canada and the United States $[12,13]$. This is unfortunate because most people with the illness desire and can work $[5,14-16]$, but they are excluded from the workforce because of stigma of the illness. For those with mental illness who are in the workforce, there are issues related to sustaining their capacity for productive work. Health Canada estimates that the loss of productivity resulting from mental illness and "disability" costs the Canadian economy $\$ 14.4$ billion annually [17]. According to the Diagnostic and Statistical Manual (DSM V), disability relevant to mental illness refers to "impairment in one or more areas of functioning as a result of mental illnesses. These may include the person's thought processes, perceptions of reality, emotions or judgments and may lead to disturbed behavior." Mental illness for the purposes of this study will include all disorders included in the DSM V. Not all individuals who are affected by mental illness may experience disability. However, a significant number of affected individuals are known to experience difficulties that interfere with their ability to learn and thus function effectively in their worker role. Mental illness can affect cognitive functioning, particularly attention, concentration, memory, thinking, reasoning, and problem solving [18]. These can be compounded by medication side effects, which may include restlessness, fatigue, drowsiness and lethargy, and memory lapses. All these factors can make it difficult for the affected employee to cope with the demands of work. Currently, mental illness and addiction account for $60-65 \%$ of all disability insurance claims among Canadian and American employers [8]. Therefore, the issue of improving employment outcomes for people with mental illness has become a priority for employers and provincial governments in Canada.

Research to improve employment outcomes for this population initially focused on understanding who respond best to vocational interventions on the basis of individual, demographic, clinical, and social variables. However, few strong associations were found between these variables and employment success defined variously in terms of job attainment, job retention, or number of hours worked $[1,2,19]$. Contemporary conceptualizations have moved beyond individually focused models to understand employment of people with mental illness as a dynamic process of interaction among several factors like the strengths, competencies, and needs of the worker, the nature of the job, and the demands of the work environment [20]. Attention is now directed to also studying factors in the work environment particularly the role of employers in assisting people with mental illness to gain and/or sustain employment and maintain productivity, health, and well-being.

\section{Research on Employer Concerns and Beliefs about Employees with Mental Illness and Disability}

Mental illness creates several barriers to employment. While the disability associated with the illness may create problems as discussed above, factors, such as poor educational achievements, stigma, lack of adequate vocational and clinical services, policy disincentives to employment, limitations of current disability support management services, legislation, and policy direction related to hiring and accommodating persons with mental health related disabilities, all add to the barriers that workers with mental health illness face $[13,21$, $22]$. One of the greatest barriers however is employer stigma and discrimination at the workplace. Surveys conducted in the US show that approximately $70 \%$ of employers are reluctant to hire someone with a history of substance abuse or someone currently taking antipsychotic medication [23], while almost a quarter would dismiss someone who had not disclosed a mental illness [24]. Also employees with mental illness are among the first employees to be retrenched in times of economic downturn [25]. The literature on employer attitudes shows that employers express a wide range of negative beliefs regarding hiring individuals with mental illness. These include concerns such as poor quantity and quality of work, brief tenure, absenteeism, and low flexibility. Employers also express concerns about the work personality of people with mental illness and these include beliefs about the need for excessive supervision, taking little pride in work, low acceptance of work role, difficulty following instructions, poor social competence, and low work persistence [26]. Employers report negative beliefs about people with mental illness with respect to factors such as motivation to work, work quantity, likelihood of injury, difficulties following directions, making friends, and becoming angry [27]. A Canadian study on stigma of mental illness defined 5 distinct assumptions held within the workplace that contribute to the disposition towards acting in a discriminatory manner: the assumption of incompetence, the assumption of dangerousness and unpredictability, the belief that mental illness is not a legitimate illness, the belief that working is unhealthy for people with mental illness, and the assumption that employing people with mental illness represents an act of charity inconsistent with workplace needs [9].

Employees with mental health problems report that once their mental illness becomes known, they experience discrimination from coworkers, feel socially marginalized, have to cope with negative comments from workmates, and have to return to positions of reduced responsibility [25, 28, 29]. Consequently, half of the competitive jobs acquired by people with mental illness end unsatisfactorily as a result of problems that occur once the job is in progress and largely as a result of interpersonal difficulties [30]. While clearly the lack of mental health literacy among employers, employees, managers, and supervisors is a prime reason for these beliefs and attitudes, there are few Canadian studies that have examined what employers know about mental illness and disability and how they deal with mental health issues in the workplace. Mental health literacy among employers will have to be addressed as a priority if people with mental illness are to be hired and retained as valued employees. This not only will help to reduce stigma, but also can enhance the likelihood of speedy identification and resolution of mental health problems in the workplace [8].

\section{Employer Diversity in Hiring Practices}

Different employers in different work environments often accommodate the needs of workers with mental illness 
differently. Research suggests that employers with previous experience of employing people diagnosed with mental health and related disability (MHRD) and employers in social service and nonprofit sector may be more willing than others to employ workers with mental illness [26, 31-33]. But there is little information on what support sectors like retail, transport, police force, and so forth need if they are to employ these workers. There is evidence that cultural backgrounds of employers influence hiring practices and willingness to accommodate the needs of workers with mental illness [34]. Company size is another factor that may influence hiring. Smaller employers may not hire workers with mental health disabilities because of concerns that they may not fit in with the physically intimate and generalist nature of small business [35]. However, much of this empirical literature comes from the United States or United Kingdom. As highlighted by Stuart [36], attempting to understand the perspectives, attitudes, concerns, and support needs of Canadian employers from data collected in social and economic systems with fundamentally different philosophical positions on work, economics, health, social welfare, workplace disability, and mental health care is fraught with difficulty as all these can impact workplace environments. There is a critical need for information on the perspectives and concerns of a range of Canadian employer groups in order to design intervention programs that target the needs of different groups and work environments.

\section{Supporting Employees with Mental Illness: Needs of Employers}

Only a small body of published information has focused on the support needs of employers [33, 37-41]. Employers may be more willing to employ if they have greater clarity about their roles and responsibilities when they hire a worker with mental illness and understand legislative requirements and the kinds of accommodations these workers may require. A recent pilot study conducted by the authors showed that employers want guidance and timely support from qualified persons like doctors or mental health workers to deal with specific issues like mental health crisis in the workplace, discussing performance issues with a worker diagnosed with mental illness, maintaining confidentiality with coworkers, and creating supportive work environments. This study also suggested that some workers with mental illness do not welcome interactions between their employers and treatment providers due to the risk of discrimination [40,41]. Canadian studies show that employers who are affiliated with an employment program within a mental health agency or who are associated with projects offering employment support to people with mental illness have more positive attitudes towards hiring these individuals [20,37]. Access to support and consultation from employment support providers can serve as an incentive to employers to employ and retain employees with mental illness. Overall, the findings suggest that direct and positive contact with workers with mental health disabilities and access to timely consultation from employment support or treatment providers can encourage positive beliefs among employers about the work capacity of people diagnosed with MHRD that may positively influence hiring decisions. Finally, there is evidence that during times of economic downturn labor force participation of people with disabilities goes down at a rate that is greater than the general population $[42,43]$. Yet there is little information on employers' experience during periods of economic downturn and the impact of this on their decision to employ or retain workers with mental illness.

\section{Policies and Program Initiatives to Improve Hiring and Retention of Workers Mental Health Related Disabilities}

Canada like Australia, the United States, United Kingdom, and many developed OECD countries has legislation that aims to reduce discrimination against people with disabilities in all areas including employment. While countries like Australia, the United States, United Kingdom, and some OECD countries have national disability legislation that protects the rights of workers with disabilities, in Canada discrimination against these workers is governed by the number of federal acts like the Canadian Human Rights Act (CHRA) (1977), the Charter of Rights and Freedoms (CRF) (1982), and the Employment Equity Act (EEA) (1986). Under these legislations, employers cannot discriminate against workers with disabilites and also have a legal duty to provide reasonable accommodations for these workers if and when they disclose their disability. A review of the legislation in these countries however shows that these are far from sufficient to promote employment for workers with disabilities. Policy instruments that are additionally required include supported employment programs, employer education, and financial incentives for employers [44].

Many countries now offer tax credits and other financial incentives to employers to employ workers with disabilities. In the United States, the Disabled Access Credit program [45] provides a nonrefundable credit for small businesses that incur expenditures for the purpose of providing access to persons with disabilities. There is also a Work Opportunity Credit program [45] that provides eligible employers with a tax credit up to 40 percent of the first $\$ 6,000$ of first-year wages of a new employee if the employee has a recognized disability. The credit is available to the employer once the employee has worked for at least 120 hours or 90 days. The Canadian Government has introduced several funding grants for small business in Ontario to improve workplace accessibility and hire skilled persons with disabilities. Many of these programs are part of Canada's Economic Action Plan to help improve the labor market opportunities and conditions for Canadians with disabilities. The Opportunities Fund for People with Disabilities, for example, provides individuals and local organizations with business funding grants to support unemployed or underemployed people with disabilities [46]. The Alberta Employment First Strategy in particular aims to increase hiring and retention of workers with disabilities by providing resources and supports for employers and enhanced employment support for people with disabilities, including youth and mental health clients [47]. Under the Australian Disability Works program, an 
employer who employs workers with disability can receive financial assistance to purchase a range of work-related modifications and services for people who are about to start a job or who are currently working. For workers with mental health conditions, the employer may be provided with mental health first aid training [48]. The Disabilities Act in Austria actively promotes the employment of severely disabled individuals by requiring employers to hire one severely disabled worker per 25 nondisabled workers. Failure to adhere to this rule can result in the employer having to pay a noncompliance tax. A review of this policy shows that the hiring obligation of the Disabilities Act in Austria has generated a positive impact on the employment of disabled workers [49].

Many of Russia's regional governments, including the administration of Moscow, have developed programs to assist disabled people in finding jobs. In conjunction with these programs, the state compensates employers for the worker's salary for one year. Due to an increase in the number of people with disabilities who gained employment due to this program, it has been implemented in many regions across of Russia. Although these are significant improvements worldwide, there is little information on whether these financial incentives for employers have led to an increase in the number of workers with mental health related disabilities gaining and sustaining employment (http://www.disabilityworld.org/0405_02/employment/russia.shtml).

In terms of programs for people with mental health related disabilities, the United States, Canada, Australia, and many other OECD countries have supported employment (SE) programs that offer individualized and intensive support to these workers as well as assisting employers in providing workplace accommodations thereby increasing the likelihood of successful employment outcomes. SE programs provide a combination of mental health and vocational support and have been shown to be the most effective one for getting people with mental illness, specifically those with serious mental health conditions into the workforce [50]. While SE programs are more costly than mainstream employment services, long-term cost savings to the health care and social assistance system have made them a desired form of employment assistance [51]. SE programs are articulated through specific models of employment services. Individual placement support (IPS) is one of the models with the most research to support its widespread use.

Since IPS has a well-established evidence base, service providers in many countries have adopted this approach in their agencies with some modifications depending on their local context. The goal of IPS is to place people in competitive employment as soon as possible without any preemployment training by assisting them to find jobs of their choice. Postemployment support is also provided to ensure long-term job tenure [52]. Researchers and mental health services are now looking to better understand the essential components of IPS so that adaptations can be made to respond to the needs of specific job seekers and local settings [53]. Hybrid models that include adding clinical interventions such as motivational interviewing and cognitive remediation have shown promise [54]. However, ongoing research and practice in the field are needed to evaluate the potential of these approaches.
Two components of the IPS approach that are of increasing concern are the lack of preemployment training and postemployment support.

A Canadian study has found that 40 percent of supported employment participants who have severe mental illness did not obtain jobs. The same study also found that job tenure was typically found to be less than five months [55]. While the IPS SE model has shown much success in creating job opportunities, the low job retention rates and quality of employment have created mixed opinions regarding its overall success. This could be because funding mechanisms for most employment support programs do not provide sufficient time to provide the full range of essential activities specified by the IPS model. A factor that has been repeatedly highlighted as a key to the success of IPS SE is the availability of long-term unlimited support. Many service providers however are able to offer only time-limited supports.

SE employment programs based on the IPS model largely address the needs of people with severe mental disorders (SMDs). According to a recent OECD study typically threefourths of those who experience mental health related disabilities have mental disorders like depression, anxiety, and substance abuse disorders, often referred to as "common mental disorders" (CMDs). Yet there is a dearth for programs and policies that address the needs of these workers. Despite being less disabling than mental disorders like schizophrenia, any of these conditions can evolve to become so severe that they could be classified as SMDs [56]. Lately there has been some increase in programs, training workshops, and online resources that aim at educating employers about their responsibilities as supervisors and provide skills to frontline supervisors/managers on dealing with performance issues of workers and crisis situations arising from mental health issues of workers. Noteworthy among these programs in Canada are Mental Health Works (http://www.mentalhealthworks.ca/) and Workplace Strategies for Mental Health initiated by GreatWest Life Centre for Mental Health in the Workplace (http:// www.workplacestrategiesformentalhealth.com/). However, little is known about the extent to which front line managers are able to access these programs due to time and resource constraints.

\section{Filling the Knowledge Gaps in the Literature}

Despite the existence of legislation and programs to increase hiring and retention of workers with mental health disabilities, many studies have consistently shown that there is little change in employers' attitudes towards hiring or accommodating these workers [44], suggesting that there are several gaps in our understanding of the role of employers in facilitating the reintegration of workers with mental illness into the workforce.

First, as discussed above, much of our understanding about employers' perspectives, attitudes, and concerns is based on research conducted in countries other than Canada. By highlighting the perspectives of employers and their understanding of mental illness, a significant contribution to the small body of the literature on mental health literacy and concerns of employers will be advanced. This will lead 
to interventions to counter employer stigma and discrimination. This approach will also help vocational rehabilitation and employment support providers to target industries that have low levels of concern about mental illness and disability for the purposes of job development, job matching, and placement.

Second, there is a dire need to educate employers on the value of employing and retaining people with mental illness as well as the need to promote and encourage workplace accommodations. Currently, funding mechanisms for most employment support programs do not provide sufficient time to provide these essential activities. Employers are also often unwilling to take a chance on including people with mental illnesses in their workforce. If employment prospects for people with mental health are to be improved, the attitudes held by employers and coworkers need to be challenged.

Third, only a small body of the published literature has explored the challenges that employers, especially front line managers, face when dealing with mental health issues in the workplace and the kinds of information and support they need to facilitate the worker's reentry and integration into the work environment. Allan [57] highlights that "from the perspective of the employer the critical issue related to health is productivity. Protecting productivity, managing risks to productivity, restoring lost productivity and maximizing productivity are all key issues for employers." Thus, the proposed research must illuminate how employers balance these perspectives with the needs of workers who experience mental illness and disability, especially in times of economic downturn and global recession and what supports they need to incorporate best practice. Current research that has attempted to examine these issues is based on small samples of employers who are affiliated with mental health agencies or supported employment programs.

\section{Conclusion}

The review of the literature provided in this paper highlights the interplay between employment integration and retention of individuals diagnosed with mental health and related disability (MHRD). The paper stressed the importance of an integrative approach, utilizing a social epidemiological approach to assess various factors that are related to the employment integration of individuals diagnosed with severe mental illness. From the review, it is clear that assessing employers' perspectives (i.e., their attitudes and concerns) on employing workers with mental illness and related disabilities and the kinds of information and support employers need to facilitate the worker retention are critical in understanding workplace mental health. Further, the review suggests that integrating quantitative and qualitative research methods can lend depth and clarity to understanding not only mental health literacy of employers, but also resources needed to support employees with severe mental health issues in the workplace. As such, research on employment integration of mentally ill workers and workplace health requires research and conceptual protocols tailored for these special populations.

The goal here is to use research approaches, frameworks, and appropriate tools to meet these objectives. Valuable information about employers' understanding of mental health and related disability (MHRD), therefore, requires a deeper understanding of concerns about why employers employ people with MHRD and the resources they need if they are to do so. Equally important is utilizing diverse methodologies and approaches to assist not only mental health epidemiologists and occupational health researchers, but also employees with MHRD, service providers, policy and decision-making bodies, teachers, academia, and the local community in finding possible interventions. It is our hope that further research in this area will yield valuable information that may lead to programs/interventions aimed at enhancing public awareness about the work capacity of people with MHRD and the supports they and their employers need if these individuals are to be successful at work. Enhanced awareness among employers and all sectors of the community will help to reduce the stigma and discrimination associated with mental illness.

At the policy level, we hope that the research will facilitate discussions around the need for healthy public policy that supports the involvement of employers and the business community in education, advocacy, and workforce development efforts that meet the needs of job seekers and the organizations employing them. Furthermore, we hope that by assessing employers' perspectives policy leaders would examine policy initiatives that support employers when they employ people with MHRD and provide appropriate workplace accommodations. Additionally, we hope that resources would be developed to support the development of intersectoral partnerships between the industry, the treatment system, and providers of vocational and employment support services; these can enhance awareness among clinicians about employment needs of consumers, encourage early referral to vocational services, and return to work (or gain employment) for individuals with MHRD. This research approach has the potential to inform the limited knowledge that currently exists in the social epidemiological field where there is increasing acknowledgement by scholars for the need for research around employment integration, workplace health, and responsive practice.

In conclusion, our review linking supportive employment, mental illness and disability, and workplace health has potential to inform epidemiological studies on mental illness and disability, specifically understanding employer perspectives on mental illness and disability, their attitudes and concerns about hiring workers with these conditions, and resources and support required to integrate and retain individuals diagnosed with mental illness and disability. Throughout our review, we have argued for an integrative approach that takes into consideration broader determinants of mental health (SDOMH). As researchers working on integrating supportive employment, mental health epidemiology, and workplace health, we grapple with how to move forward this research agenda and our review of the literature offers a unique and integrative approach to assess the interplay between employment integration and retention of individuals diagnosed with mental illness and disability. We hope that this approach will pave a way for collaborative demonstration projects between mental health rehabilitation, social epidemiologists, social workers, employment support providers, and the business industry. 


\section{Conflict of Interests}

The authors declare that there is no conflict of interests regarding the publication of this paper.

\section{References}

[1] W. A. Anthony, "Characteristics of people with psychiatric disabilities that are predictive of entry into the rehabilitation process and successful employment outcomes," Psychosocial Rehabilitation Journal, vol. 17, pp. 3-14, 1994.

[2] P. G. Arns and J. A. Linney, "Work, self and life satisfaction for persons with severe and persistent mental disorders," Psychosocial Rehabilitation Journal, vol. 17, pp. 63-80, 1993.

[3] G. R. Bond, R. E. Drake, K. T. Mueser, and D. R. Becker, "An update on supported employment for people with severe menial illness," Psychiatric Services, vol. 48, no. 3, pp. 335-346, 1997.

[4] R. Bland, "Mental Health in Alberta: updates of interest," in Proceedings of the CMHA Annual Meeting, 2006.

[5] G. R. Bond, R. E. Drake, and D. R. Becker, "An update on randomized controlled trials of evidence-based supported employment," Psychiatric Rehabilitation Journal, vol. 31, no. 4, pp. 280-290, 2008.

[6] National Mental Health Association, "Supported employment for persons with psychiatric disabilities: a review of effective services," July 2005, http://nmha.org/pedu/adult/supported_ employment.pdf.

[7] J. H. Noble, R. S. Honberg, L. Lee Hall, and L. M. Flynn, "Nami executive summary," Journal of Disability Policy Studies, vol. 10, no. 1, pp. 10-17, 1999.

[8] M. Kirby, "Out of the shadows at last-transforming mental health, mental illness and addiction services in Canada," Final Report of the Standing Senate Committee on Social Affairs, Science and Technology, 2006.

[9] T. Krupa, B. Kirsh, L. Cockburn, and R. Gewurtz, "A model of stigma of mental illness in employment," Work, vol. 33, no. 4, pp. 413-425, 2009.

[10] D. Gilbride, R. Stensrud, C. Ehlers, E. Evans, and C. Peterson, "Employers' attitudes toward hiring persons with disabilities and vocational rehabilitation services," Journal of Rehabilitation, vol. 66, no. 4, pp. 17-23, 2000.

[11] M. McQuilken, J. H. Zahniser, J. Novak, R. D. Starks, A. Olmos, and G. R. Bond, "The work project survey: consumer perspective on work," Journal of Vocational Rehabilitation, vol. 18, no. 1, pp. 59-68, 2003.

[12] K. Sanderson and G. Andrews, "Common mental disorders in the workforce: recent findings from descriptive and social epidemiology," Canadian Journal of Psychiatry, vol. 51, no. 2, pp. 63-75, 2006.

[13] A. A. Murphy, M. G. Mullen, and B. Spagnolo, "Enhancing individual placement and support: promoting job tenure by integrating natural supports and supported education," The American Journal of Psychiatric Rehabilitation, vol. 8, pp. 37-61, 2005.

[14] K. W. D. Liu, V. Hollis, S. Warren, and D. L. Williamson, "Supported-employment program processes and outcomes: experiences of people with Schizophrenia," The American Journal of Occupational Therapy, vol. 61, no. 5, pp. 543-554, 2007.

[15] C. Macias, L. T. DeCarlo, Q. Wang, J. Frey, and P. Barreira, "Work interest as a predictor of competitive employment: policy implications for psychiatric rehabilitation," Administration and Policy in Mental Health, vol. 28, no. 4, pp. 279-297, 2001.
[16] G. Morgan, "We want to be able to work," Mental Health Today, pp. 32-34, 2005.

[17] T. Stephens and N. Joubert, "The economic cost of mental health problems in Canada," Chronic Diseases in Canada, vol. 22, pp. 18-23, 2001, http://www.phac-aspc.gc.ca/publicat/cdicmcc/22-1/d_e.html.

[18] W. Spaulding and M. Sullivan, "From laboratory to clinic: psychological methods and principles in psychiatric rehabilitation," in Handbook of Psychiatric Rehabilitation, R. P. Liberman, Ed., vol. 166, pp. 30-55, 1992.

[19] S. R. McGurk, K. T. Mueser, P. D. Harvey, R. LaPuglia, and J. Marder, "Cognitive and symptom predictors of work outcomes for clients with schizophrenia in supported employment," Psychiatric Services, vol. 54, no. 8, pp. 1129-1135, 2003.

[20] B. Kirsh, T. Krupa, L. Cockburn, and R. Gewurtz, "Work initiatives for persons with severe mental illnesses in Canada: a decade of development," Canadian Journal of Community Mental Health, vol. 25, no. 2, pp. 173-191, 2006.

[21] J. A. Cook, "Employment barriers for persons with psychiatric disabilities: update of a report for the president's commission," Psychiatric Services, vol. 57, no. 10, pp. 1391-1405, 2006.

[22] L. Cockburn, T. Krupa, J. Bickenbach et al., "Work and psychiatric disability in Canadian disability policy," Canadian Public Policy, vol. 32, no. 2, pp. 197-211, 2006.

[23] T. L. Scheid, "Employment of individuals with mental disabilities: business response to the ADA's challenge," Behavioral Sciences \& the Law, vol. 17, pp. 73-91, 1999.

[24] N. Sartorius and H. Schulze, Reducing Stigma due to Mental Illness: A Report from a Global Program of the World Psychiatric Association, Cambridge University Press, 2005.

[25] H. Stuart, "Mental illness and employment discrimination," Current Opinion in Psychiatry, vol. 19, no. 5, pp. 522-526, 2006.

[26] E. Diksa and E. S. Rogers, "Employer concerns about hiring persons with psychiatric disability: results of the employer attitude questionnaire," Rehabilitation Counseling Bulletin, vol. 40, no. 1, pp. 31-44, 1997.

[27] J. A. Cook, L. A. Razzano, D. M. Straiton, and Y. Ross, "Cultivation and maintenance of relationships with employers of people with psychiatric disabilities," Psychosocial Rehabilitation Journal, vol. 17, no. 3, pp. 103-116, 1994.

[28] O. F. Wahl, "Mental health consumers' experience of stigma," Schizophrenia Bulletin, vol. 25, no. 3, pp. 467-478, 1999.

[29] B. Schulze and M. C. Angermeyer, "Subjective experiences of stigma. A focus group study of schizophrenic patients, their relatives and mental health professionals," Social Science and Medicine, vol. 56, no. 2, pp. 299-312, 2003.

[30] D. R. Becker, R. E. Drake, G. R. Bond, H. Xie, B. J. Dain, and K. Harrison, "Job terminations among persons with severe mental illness participating in supported employment," Community Mental Health Journal, vol. 34, no. 1, pp. 71-82, 1998.

[31] N. E. Khalema and N. Eshkakogan, Recruitment and Retention of Human Service Personnel in the Human Service Sector: A Research Report, Government of Alberta Children and Youth Services Branch and MacEwan Institute for Research on Family \& Youth, 2008.

[32] J. M. Levy, D. J. Jessop, A. Rimmerman, and P. H. Levy, "Employment of persons with severe disabilities in large businesses in the United States," International Journal of Rehabilitation Research, vol. 14, no. 4, pp. 323-332, 1991.

[33] C. Hand and J. Tryssenaar, "Small business employers' views on hiring individuals with mental illness," Psychiatric Rehabilitation Journal, vol. 29, no. 3, pp. 166-173, 2006. 
[34] H. W. H. Tsang, B. Angell, P. W. Corrigan et al., "A crosscultural study of employers' concerns about hiring people with psychotic disorder: implications for recovery," Social Psychiatry and Psychiatric Epidemiology, vol. 42, no. 9, pp. 723-733, 2007.

[35] B. Angell, M. Spitzmueller, and P. Corrigan, "Stigma in the hiring process: employer perceptions of mental illness and substance abuse," in Work and Well-being Research and Evaluation Program, Centre for Addiction and Mental Health, 2009.

[36] H. Stuart, "Stigma and work," Health Papers, vol. 5, pp. 100-111, 2004.

[37] C. Mizzoni and B. Kirsh, "Employer perspectives on supervising individuals with mental health problems," Canadian Journal of Community Mental Health, vol. 25, no. 2, pp. 193-206, 2006.

[38] M. L. Kirzner, R. Baron, and I. Rutman, Employer Participation in Supported and Transitional Employment for Persons with Long Term Mental Illness, Matrix Research Institute, Philadelphia, Pa, USA, 1992.

[39] L. Cockburn, B. Kirsh, T. Krupa, and R. Gewurt, "Mental health in the workplace: why businesses are paying attention," Occupational Therapy Now, vol. 6, no. 5, 2004.

[40] J. Shankar and F. Collyer, "Support needs of people with mental illness in vocational rehabilitation programs: the role of the social network," International Journal of Psychosocial Rehabilitation, vol. 7, pp. 15-28, 2003.

[41] J. Shankar, "The role of ongoing support in improving job tenure for people who experience psychiatric disability," Fourth Annual Mental Health Showcase, Alberta, Canada, 2008.

[42] R. Warner, Recovery from Schizophrenia: Psychiatry and Political Economy, Routledge, London, UK, 1994.

[43] E. Yelin, "The impact of labor market trends on the employment of persons with disabilities," American Rehabilitation, vol. 26, pp. 21-33, 2001.

[44] M. J. Prince, "What about a disability rights act for Canada? Practices and lessons from America, Australia and United Kingdom," Canadian Public Policy, vol. 36, no. 2, pp. 199-214, 2010.

[45] Internal Revenue Service IRS, 2013, http://www.irs.gov/Businesses/Small-Businesses-\&-Self-Employed/Tax-Benefits-forBusinesses-Who-Have-Employees-with-Disabilities.

[46] Service Canada, 2013, http://www.servicecanada.gc.ca/eng/of/ index.shtml?utm_source=Opportunities + Fund + for + Persons + with+Disabilities\&utm_medium=Link\&utm_campaign=Action_ Plan_Skills_Fall_2013.

[47] Alberta Human Services, "Employment First Strategy. Making Progress," 2014, http://humanservices.alberta.ca/disabilityservices/employment-first.html.

[48] Australian Disability Employment Services, 2014, http://www .humanservices.gov.au/customer/services/centrelink/disabilityemployment-services.

[49] Disabilities Act in Austria, 2014, http://www.ohchr.org/Documents/Issues/Disability/SubmissionWorkEmployment/ResponseAustria.pdf.

[50] M. Corbière, N. Lanctôt, T. Lecomte et al., "A pan-canadian evaluation of supported employment programs dedicated to people with severe mental disorders," Community Mental Health Journal, vol. 46, no. 1, pp. 44-55, 2010.

[51] E. Latimer, "An effective intervention delivered at sub-therapeutic dose becomes an ineffective intervention," The British Journal of Psychiatry, vol. 196, no. 5, pp. 341-342, 2010.

[52] G. R. Bond, R. E. Drake, and D. R. Becker, "An update on randomized controlled trials of evidence-based supported employment," Psychiatric Rehabilitation Journal, vol. 31, no. 4, pp. 280290, 2008.
[53] M. P. Salyers, A. B. McGuire, G. R. Bond et al., "What makes the difference? Practitioner views of success and failure in two effective psychiatric rehabilitation approaches," Journal of Vocational Rehabilitation, vol. 28, no. 2, pp. 105-114, 2008.

[54] S. R. McGurk, K. T. Mueser, K. Feldman, R. Wolfe, and A. Pascaris, "Cognitive training for supported employment: 2-3 year outcomes of a randomized controlled trial," The American Journal of Psychiatry, vol. 164, no. 3, pp. 437-441, 2007.

[55] M. Corbière, N. Lanctôt, T. Lecomte et al., "A pan-canadian evaluation of supported employment programs dedicated to people with severe mental disorders," Community Mental Health Journal, vol. 46, no. 1, pp. 44-55, 2010.

[56] OECD Mental Health Work Project, Sick on the Job? Myths and Realities about Mental Health and Work, 2011.

[57] P. Allan, "For employer productivity is critical," Health Care Papers, vol. 5, no. 2, pp. 95-97, 2005. 


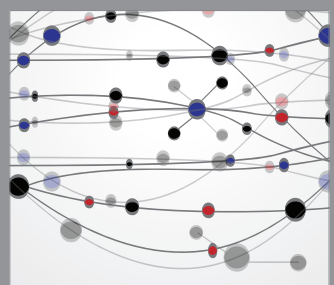

The Scientific World Journal
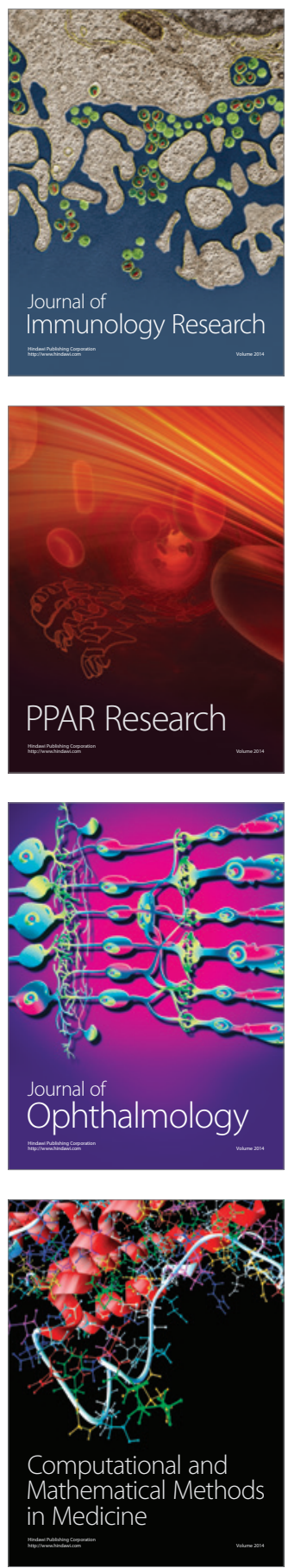

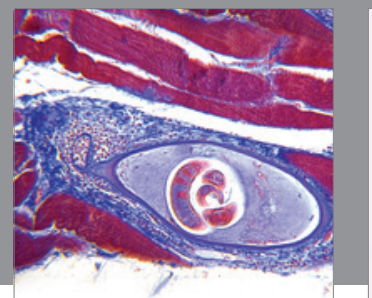

Gastroenterology

Research and Practice
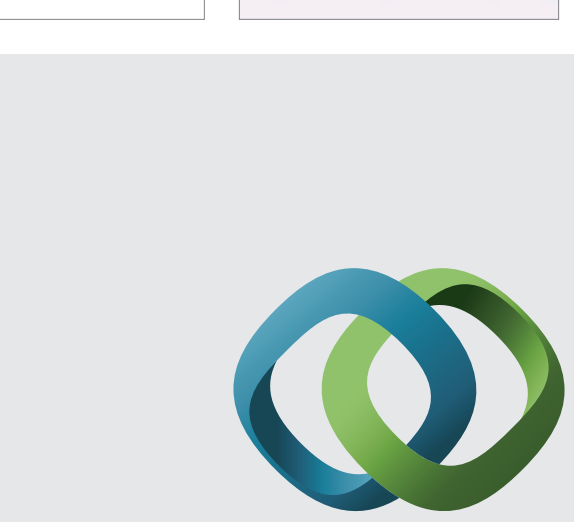

\section{Hindawi}

Submit your manuscripts at

http://www.hindawi.com
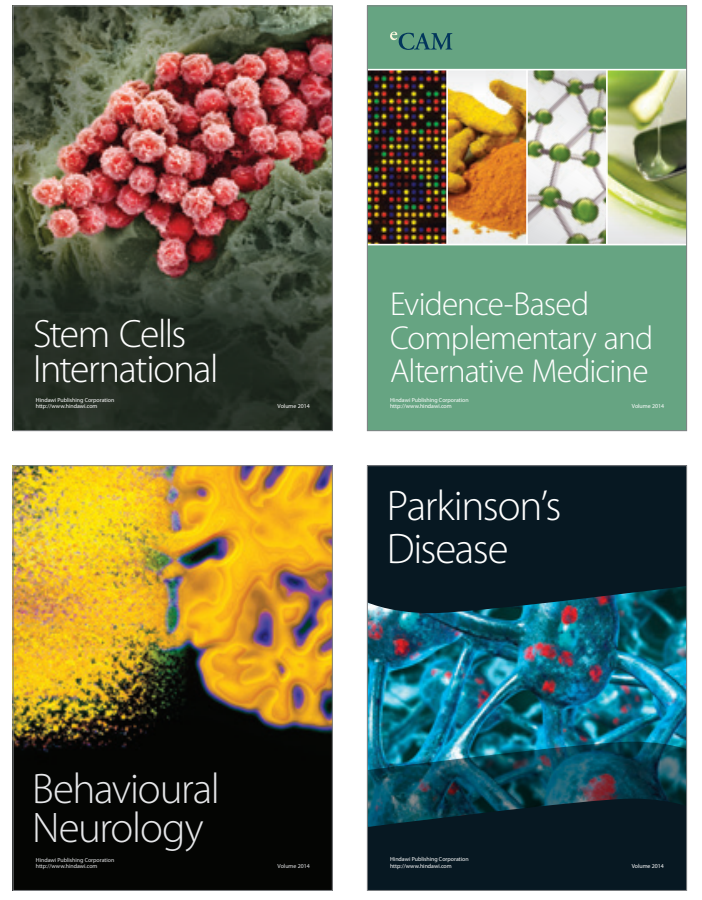
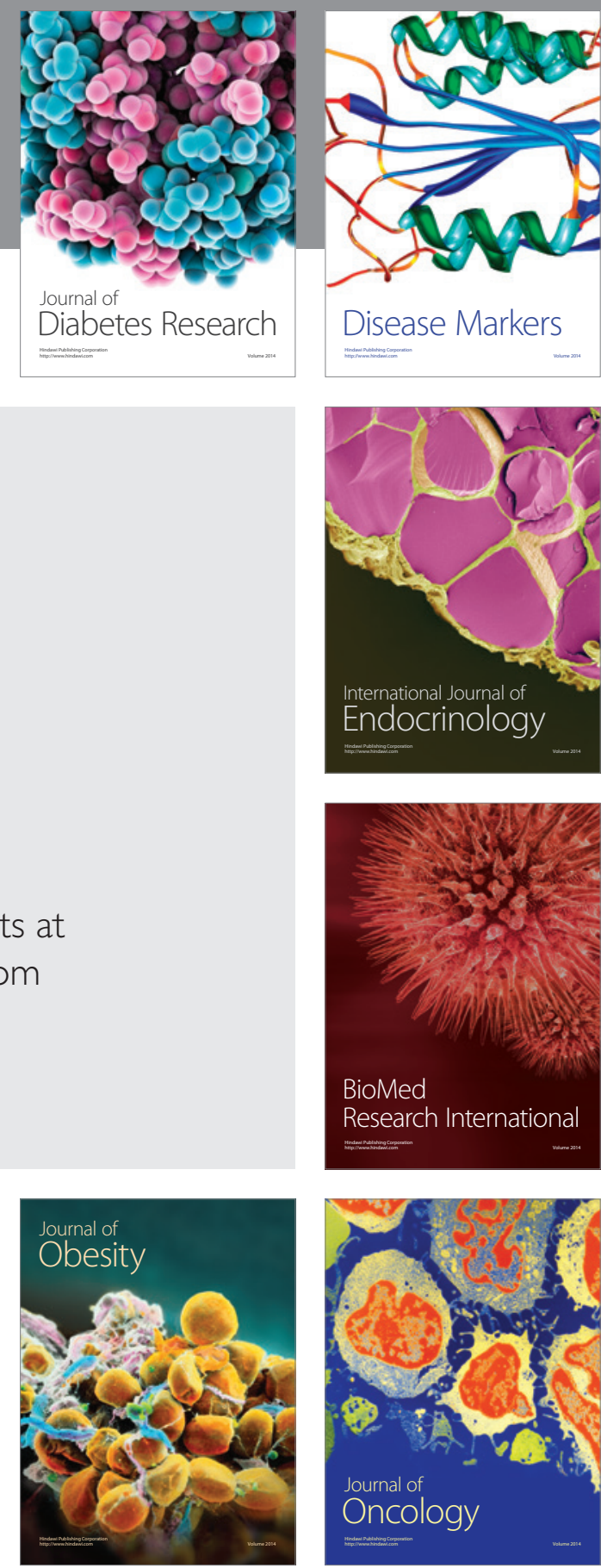

Disease Markers
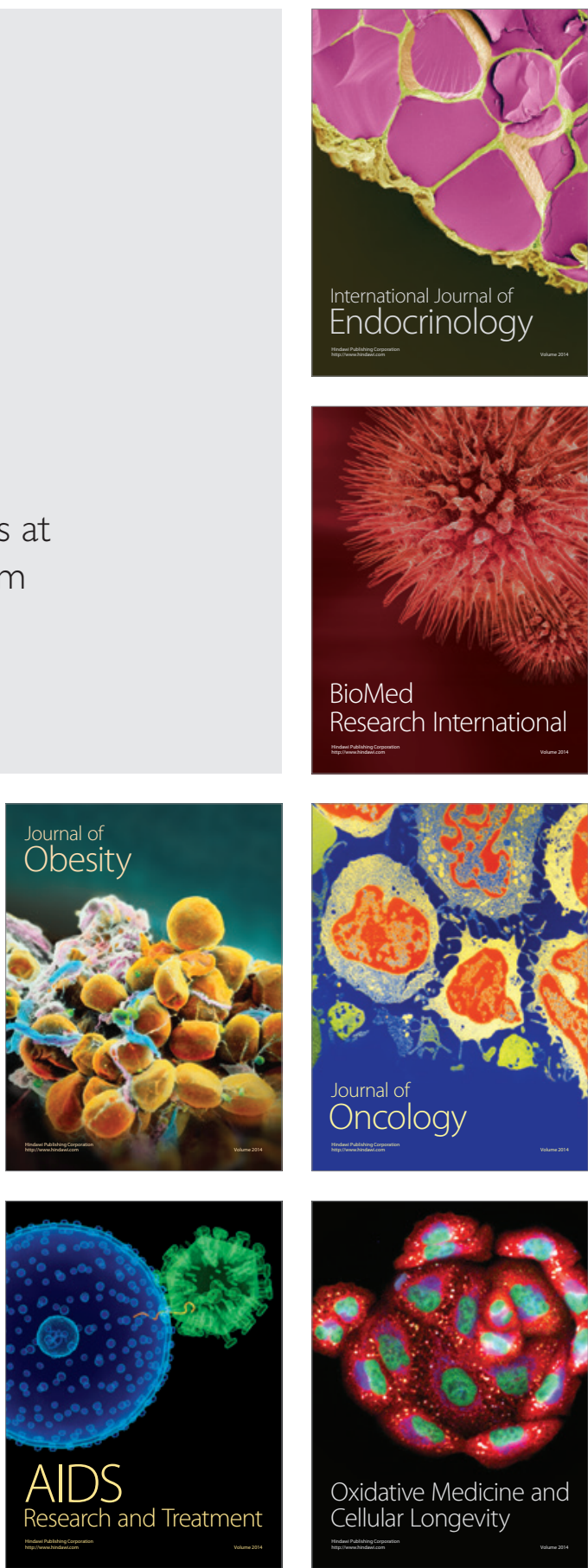